\title{
Estudos de (inter)midialidade: uma proposta efetivamente interdisciplinar
}

\author{
Elaine Indrusiak' \\ https://orcid.org/0000-0002-0297-2554 \\ I - UFRGS \\ Porto Alegre (RS). Brasil
}

ELLESTRÖM, L. Midialidade. Ensaios

Sobre Comunicação, Semiótica

e Intermidialidade. Porto Alegre:

EDIPUCRS, 2017. 273p.

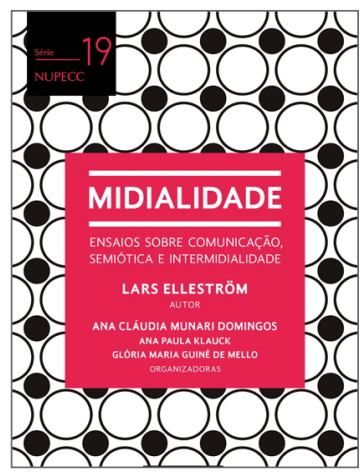

Resumo: Midialidade: ensaios sobre comunicação, semiótica e intermidialidade reúne sete ensaios de Lars Ellestöm, destacado pesquisador dos estudos de (inter)midialidade e de suas relações com áreas afins. A publicação dos textos traduzidos disponibiliza, para o público brasileiro, um panorama geral dos modelos teóricos e propostas metodológicas do autor para a sistematização dos estudos intermídia.

Palavras-chave: comunicação; semiótica; intermidialidade

Abstract: Studies of (inter)mediality: a too much interdisciplinary proposal - Midialidade: ensaios sobre comunicação, semiótica e intermidialidade gathers seven essays by Lars Elleström, prominent researcher in (inter)mediality and its related areas. The publishing of the translated texts provides the Brazilian public with a panoramic view of Elleström's theoretical models and methodological proposals for the systematization of intermedia studies.

Keywords: communication; semiotics; intermediality

Midialidade: ensaios sobre comunicação, semiótica e intermidialidade reúne sete ensaios de Lars Elleström (2017), professor da Universidade de Linnaeus e coordenador da International Society for Intermedial Studies - ISIS. Os ensaios traduzidos sintetizam parte de sua vasta produção, que perpassa as áreas da literatura comparada, da comunicação, 
da linguística e da semiótica. Tamanha amplitude não atesta apenas a diversidade dos interesses e a erudição do autor, mas condiz com seu projeto de aproximação e efetiva colaboração das diferentes áreas diretamente relacionadas ao conceito de mídia e seus correlatos. Não se trata de uma mera coletânea de reflexões acerca de interesses comuns a tais disciplinas, mas da reunião de propostas concretas de conceitos, de terminologia padronizada e de modelos e metodologias de análise dos fenômenos comunicacionais e midiáticos que atendam a investigações pautadas por objetos e propósitos diversos.

O primeiro capítulo, Um modelo de comunicação centralizado na mídia, já evidencia a proposta aglutinadora de Elleström, apresentando uma análise crítica dos modelos de comunicação de Shannon (1948), Jakobson (1960), Schramm (1971) e Hall (1980) para, então, delinear um novo modelo capaz de contemplar significados não verbais e centrado na mídia, entendida aqui como etapa ou espaço intermediário da comunicação. Sua proposta parte da definição dos elementos indispensáveis à comunicação e das interrelações essenciais entre tais entidades nos atos comunicacionais. Ao substituir o conceito de mensagem pelo de valor cognitivo, o autor evita dicotomias falaciosas, como texto vs. imagem, ou verbal vs. visual. Já o caráter não redutível do modelo permite a adição de outros elementos atuantes nas diversas formas de comunicação, evidenciando ampla aplicabilidade interdisciplinar.

O segundo ensaio é intitulado As modalidades das mídias: um modelo para a compreensão das relações intermidiáticas. Retomando e aprofundando a questão da pluralidade de acepções do termo mídia, o autor propõe a subdivisão do conceito em mídias básicas, qualificadas e técnicas. A seguir, enumera e analisa as modalidades das mídias, características elementares que conferem ao complexo midiático a materialidade, a percepção e a cognição. Com isso, delineia-se uma metodologia de análise intermidiática pautada pelas características fundamentais comuns a todas as mídias.

Representação material e mental: Peirce adaptado aos estudos das mídias e das artes traz um criterioso estudo da obra do semioticista C. S. Peirce (1932). Admitindo a parcialidade de sua leitura da abrangente semiótica peirceana, Elleström descarta seus aspectos estritamente matemáticos e lógicos para destacar as questões de efetiva relevância para os estudos das mídias e das artes. A partir da sistematização da tricotomia peirceana e de outros conceitos centrais à semiótica e às ciências da cognição, o autor esboça um Modelo de Representação Material e Mental (RMM) e propõe uma moldura teórica para uma semiótica das mídias.

Adaptação no campo das transformações das mídias defende a ampliação do escopo dos estudos de adaptação. Excessivamente centrados, segundo Elleström, nas relações entre literatura e cinema, tais estudos deveriam visar diálogos e transformações entre todos os tipos de artes e de mídias. Nesse sentido, o autor propõe a transmidialidade como perspectiva analítica para dar conta de tais contatos intersemióticos. Entendida como um entre diversos tipos de transmidiação, a adaptação teria muito a ganhar em sistematização ao compartilhar o referencial teórico e terminológico dos estudos de intermidialidade. 
Estabelecidas as bases teóricas e metodológicas do projeto de Elleström, os capítulos finais têm caráter mais aplicado. Em Adaptação e intermidialidade, o autor reitera a argumentação do ensaio anterior, acrescentando análises de casos fronteiriços dos estudos de adaptação que tendem a se beneficiar de uma abordagem intermidiática. Transferência de características das mídias entre mídias diferentes estabelece a distinção entre mediação e representação, elenca os traços elementares das mídias para, então, propor um novo enquadramento teórico que dê conta das transformações das mídias, com especial atenção às perdas de dados nos trânsitos intermediais. Por fim, Os paradoxos da arte postal: como construir um tipo de mídia de arte, foca na arte postal, nascida do desejo pela livre circulação de obras de arte e posteriormente cooptada pelo circuito convencional das galerias. Partindo de contradições internas do gênero, Elleström aborda um quadro complexo e instigante das instâncias de produção, legitimação, circulação e consumo de arte e produtos de mídia.

A síntese do pensamento de Elleström é de grande relevância à comunicação e áreas afins, e a proposta editorial é ainda mais louvável pela disponibilização gratuita do livro, que pode ser encontrado em http://editora.pucrs.br/livro/midialidade/.

Elaine Indrusiak é professora do Departamento de Línguas Modernas e do Programa de Pós-Graduação em Letras da Universidade Federal do Rio Grande do Sul.

elaine.indrusiak@ufrgs.br

\section{Referências}

ELLESTRÖM, L. Midialidade. Ensaios Sobre Comunicação, Semiótica e Intermidialidade. Porto Alegre: EDIPUCRS, 2017. 273p.

HALL, S. Culture, media, language: Working papers in cultural studies, 1972-79. Londres: Hutchinson, 1980.

JAKOBSON, R. Closing Statement: Linguistics and poetics. In: SEBEOK, T. (Ed.). Style in Language. New York: Willey, 1960, p. 350-377.

PEIRCE, C. S. Collected Papers of Charles Sanders Peirce, vol. II. Edição de Charles Hartshorne e Paul Weiss. Cambridge, MA: Harvard University Press, 1932.

SCHRAMM, W. The nature of communication between humans. In: SCHRAMM, W.; ROBERTS, D. F. (Eds.). The process and effects of mass communication. Ed. Revisada, Urbana: University of Illinois Press, 1971, p. 3-53.

SHANNON, C. E. A mathematical theory of communication. The Bell System Technical Journal, v. 27,1948, p. 379-423. 